\title{
Identification of differentially expressed genes and biological pathways in para-carcinoma tissues of HCC with different metastatic potentials
}

\author{
YAN LIU ${ }^{1 *}$, MINGMING DENG ${ }^{2 *}$, YIMENG WANG $^{1}$, HUIQIN WANG ${ }^{1},{\mathrm{CHANGPING} \mathrm{LI}^{2} \text { and HAO WU }}^{3}$ \\ ${ }^{1}$ Department of Gastroenterology, The Chengdu Fifth People's Hospital, Chengdu, Sichuan 611130; \\ ${ }^{2}$ Department of Gastroenterology, The Affiliated Hospital of Southwest Medical University, \\ Luzhou, Sichuan 646000; ${ }^{3}$ Department of Hepatobiliary Surgery, \\ The Second Affiliated Hospital of Chongqing Medical University, Chongqing 400016, P.R. China
}

Received July 22, 2019; Accepted January 30, 2020

DOI: $10.3892 / \mathrm{ol} .2020 .11493$

\begin{abstract}
Hepatocellular carcinoma (HCC) is a malignant tumor with extensive metastasis. Changes in the tumor microenvironment provide favorable conditions for tumor metastasis. However, the role of changes to the tumor microenvironment in $\mathrm{HCC}$ metastasis is yet to be elucidated. The Gene Expression Omnibus expression profile GSE5093 consists of 20 noncancerous tissues surrounding HCC tissues, including 9 metastasis-inclined microenvironment samples with detectable metastases and 11 metastasis-averse microenvironment samples without detectable metastases. The present study assessed $35 \mathrm{HCC}$ samples to verify the results of chip analysis. In total, 712 upregulated and 459 downregulated genes were identified, with 1,033 nodes, 7,589 edges and 10 hub genes. Gene ontology and Kyoto Encyclopedia of Genes and Genomes pathway analysis revealed that the differentially expressed genes were significantly enriched in 'cell-cell adhesion', 'cell proliferation' and 'protein binding'. The top 10 hub genes were identified via a protein-protein interaction analysis. The 3 most significant modules were identified from the protein-protein network. Moreover, an association between hub genes and patient prognosis was identified. In conclusion,
\end{abstract}

Correspondence to: $\mathrm{Dr}$ Changping $\mathrm{Li}$, Department of Gastroenterology, The Affiliated Hospital of Southwest Medical University, 25 Taiping Street, Luzhou, Sichuan 646000, P.R. China E-mail: 506854209@qq.com

Dr Hao Wu, Department of Hepatobiliary Surgery, The Second Affiliated Hospital of Chongqing Medical University, 76 Linjiang Road, Chongqing 400016, P.R. China

E-mail: whwhcq@126.com

*Contributed equally

Key words: hepatocellular carcinoma, tumor microenvironment, differentially expressed genes, enrichment analysis, protein-protein interaction, prognosis these candidate genes and pathways may help elucidate the mechanisms underlying HCC metastasis and identify more options for targeted therapy.

\section{Introduction}

Hepatocellular carcinoma (HCC) is the major histological subtype of primary liver cancer accounting for $85 \%$ of all liver cancer cases worldwide, and it was reported to be the most common liver malignancy in 2016 (1). HCC is one of the most aggressive types of cancer with a high mortality rate, whereby 326,000 people died of HCC in 2015 (2). There are several definite risk factors for $\mathrm{HCC}$, such as chronic hepatitis $\mathrm{B} / \mathrm{C}$ virus infection, nonalcoholic fatty liver diseases, aflatoxin consumption and smoking (2). In addition, there have been a number of identified prognostic markers of HCC, such as alpha fetoprotein, vascular endothelial growth factor and transforming growth factor $\beta$, in both large-scale clinical trials and research projects. However, the early diagnosis and effective treatment of $\mathrm{HCC}$ remains problematic (3).

To date, surgical resection remains the gold standard treatment for HCC; however, postoperative recurrence and metastasis is common (4). In addition, a large number of patients with HCC are diagnosed at the advanced stages, in which the tumor has already metastasized to other organs prior to surgery (4). Therefore, metastasis is a key challenge in the treatment of HCC. Tumor metastasis is a malignant biological process involving multiple factors and complex signaling pathways that depend not only on the genetic changes of malignant tumor cells, but also on the changes in the tumor microenvironment, such as the stroma, blood vessels and infiltrating inflammatory cells (5). Dysfunction of gene expression in the microenvironment surrounding a tumor serves an important role in the metastatic behavior of tumor cells, such as adhesion of tumor cells, degradation of the extracellular matrix, invasion of basal tissues, homing ability to enter specific tissues, movement and migration in the circulatory system and the promotion of the angiogenesis (6). Therefore, the identification of key genes which function in the tumor microenvironment 
of HCC may be helpful to identify new targeted therapeutic strategies for HCC metastasis.

In the present study, an original dataset (GSE5093) was obtained from the NCBI-Gene Expression Omnibus database (ncbi.nlm.nih.gov/geo/) containing 20 samples of noncancerous tissues surrounding $\mathrm{HCC}$ tissues from two distinct groups of patients with HCC, including 9 metastasis-inclined microenvironment (MIM) samples, with detectable metastases and 11 metastasis-averse microenvironment (MAM) samples, without detectable metastases (7). Differentially expressed genes (DEGs) were filtered in using the Morpheus Website with a data processing standard. Gene-Spring software (version 13.1.1; Agilent Technologies Inc.) was employed to screen the DEGs, followed by Gene Ontology (GO) and Kyoto Encyclopedia of Genes and Genomes (KEGG; kegg.jp) pathway enrichment analysis. Furthermore, a protein-protein interaction (PPI) network was established and three significant modules were analyzed. A total of $35 \mathrm{HCC}$ tissue samples were assessed to verify the results of chip analysis. The present study aimed to investigate the genetic molecular mechanisms underlying the metastatic phenotype of HCC and improve the diagnosis and treatment of metastases of primary hepatic carcinoma patients.

\section{Materials and methods}

Data collection. The gene expression profile GSE5093 was obtained from Gene Expression Omnibus (GEO) (7). The GSE5093 dataset was based on the GPL1262 dataset [National Cancer Institute (NCI)/Advanced Technology Corner (ATC) Hs-UniGEM2, Advanced Technology Center Microarray Facility (National Institutes of Health (NIH)/NCI/Cancer Research Center (CCR)/ATC)] and contained 20 samples, including 9 MIM samples and 11 MAM samples.

Patients and specimens. The present study was approved by The Institutional Review Board of the Second Affiliated Hospital of Chongqing Medical University (Chongqing, China) and written informed consent was provided by all patients according to The Declaration of Helsinki. A total of $35 \mathrm{HCC}$ specimens (from 21 men and 14 women; age range, 22-73 years; mean age, 53 years) were collected during resection of HCC tumor at The Second Affiliated Hospital of Chongqing Medical University (Chongqing, China) between May 2015 and November 2016. Tissue samples included 16 noncancerous surrounding hepatic tissue samples with MIM and 19 noncancerous surrounding hepatic tissue samples with MAM ( $<5 \mathrm{~cm}$ away from HCC tissue). Specimens were stored in liquid nitrogen for subsequent experimentation. The clinicopathological features of the HCC specimens are listed in Table SI.

Identification and analysis of DEGs. MIM and MAM samples were divided into two groups and GEO2R (ncbi.nlm.nih. gov/geo/geo2r/) was used to analyze the DEGs between the two groups. The raw expression data files, which included TXT files (Agilent platform), were used for analysis by processing using the Morpheus Website (software.broadinstitute.org). A unpaired t-test was used to identify the DEGs and llog fold change $(\mathrm{FC}) \mid \geq 1$ and $\mathrm{P}<0.05$ were used as the cut-off criteria for statistical significance.
Functional and pathway enrichment of DEGs. After identifying the DEGs, GO enrichment and KEGG pathway analyses were performed for gene annotation and functional enrichment analysis using the online tool Database for Annotation, Visualization and Integrated Discovery (DAVID; david.abcc. ncifcrf.gov/). The resulting GO terms and KEGG pathways with $\mathrm{P}<0.05$ were considered significantly enriched for the obtained DEGs.

Survival analysis of the hub genes in HCC. Kaplan-Meier survival analysis and the log-rank test were employed to determine the association between hub genes and HCC, using the Gene Expression Profiling Interactive Analysis (GEPIA) database (8) and prognostic data from The Cancer Genome Atlas (cancer.gov/tcga) database. The percentage of low and high expression groups was set at $50 \%$.

Constructing the PPI network of DEGs. The Search Tool for the Retrieval of Interacting Genes (STRING) database offers both experimental and predicted interactive information (9). In the present study, the STRING database was used to explore the enrichment analysis results according to the biological process, molecular function and cell components determined for the DEGs. Finally, the interactions were selected, of which combined scores of $>0.7$ were used to construct the PPI network using the Molecular Complex Detection (MCODE) plugin within Cytoscape software [version 3.7.2; (10,11)].

$R N A$ preparation and reverse transcription-quantitative $(R T-q) P C R$. Total RNA from tissue samples was extracted using TRIzol ${ }^{\circledR}$ reagent (Takara Bio, Inc.), according to the manufacturer's protocol. RNA was reverse transcribed into cDNA using the PrimeScript RT reagent (Takara Bio, Inc.). The temperature protocol for RT was as follows: $37^{\circ} \mathrm{C}$ for $5 \mathrm{~min}$, followed by $45^{\circ} \mathrm{C}$ for $42 \mathrm{~min}$ and $75^{\circ} \mathrm{C}$ for $5 \mathrm{~min}$. qPCR was subsequently performed using SYBR-Green Real-time PCR Master mix (Beijing Transgen Biotech Co., Ltd.). The primer sequences used for qPCR are listed in Table SII. The following thermocycling conditions were used for qPCR: Initial denaturation at $92^{\circ} \mathrm{C}$ for $15 \mathrm{~min} ; 37$ cycles of $95^{\circ} \mathrm{C}$ for $15 \mathrm{sec}, 55^{\circ} \mathrm{C}$ for $30 \mathrm{sec}$; and a final extension at $72^{\circ} \mathrm{C}$ for $30 \mathrm{sec}$. Relative mRNA levels were measured using the $2^{-\Delta \Delta \mathrm{Cq}}$ method (12) and normalized to the internal reference gene GAPDH.

Statistical analysis. All data are presented as the mean \pm standard deviation and analyzed using SPSS 20.0 software (IBM Corp.) and GraphPad Prism 7 (GraphPad Software, Inc.). Differences between groups were analyzed using paired Student's t-test and one-way analysis of variance, followed by Newman-Keuls post hoc test. $\mathrm{P}<0.05$ was considered to indicate a statistically significant difference.

\section{Results}

Identification of DEGs between MIM and MAM samples. Through the analysis and processing of data in GSE5093, a total of 1,171 DEGs were identified, which included 712 upregulated and 459 downregulated genes. The heat map of DEG expression levels (top 50 upregulated and 50 downregulated genes) is exhibited in (Fig. 1). 


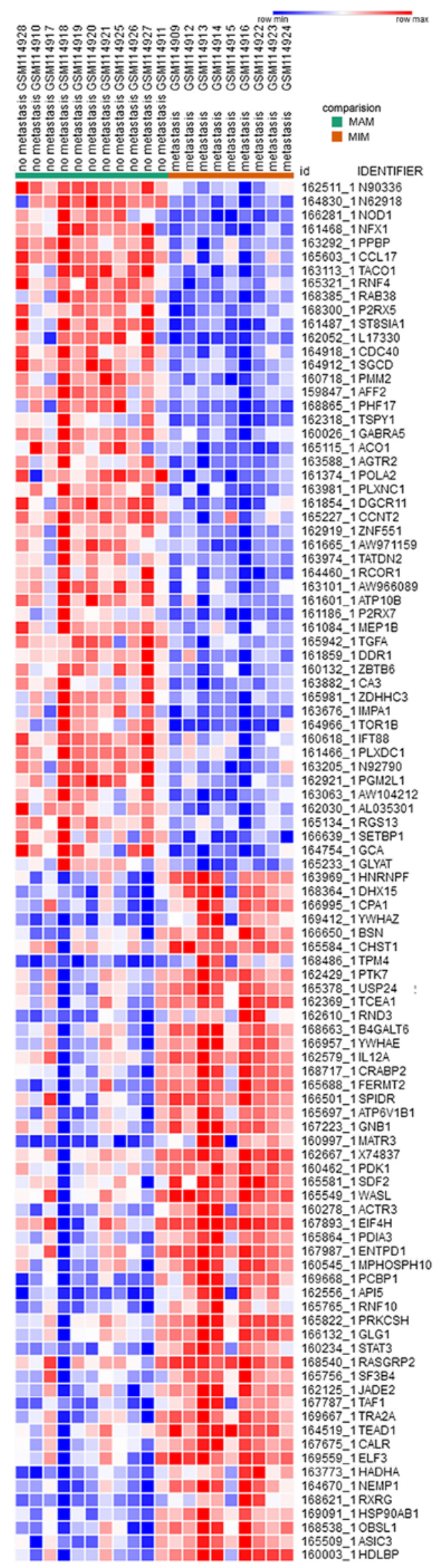

Figure 1. Heat map of the top 100 differentially expressed genes in metastasis-inclined microenvironment and metastasis-averse microenvironment samples (50 upregulated and 50 downregulated genes). Red, upregulation; blue, downregulation.
GO and pathway enrichment analyses of DEGs. The 1,171 DEGs were selected for functional analysis, performed using the DAVID database. GO analysis of DEGs was carried out from three aspects, which covered molecular function (MF), cellular component (CC) and biological process (BP). BP analysis revealed that the upregulated DEGs were enriched in 'cell-cell adhesion', 'mRNA splicing via spliceosome' and 'platelet degranulation' (Table I), whereas the downregulated DEGs were enriched in 'cell-cell adhesion', 'cell proliferation' and 'positive regulation to tyrosine phosphorylation of STAT5 protein' (Table II). For CC, the upregulated DEGs were enriched in the 'extracellular exosome and cytosol', as well as the 'membrane' (Table I) and the downregulated DEGs were enriched in 'receptor complex', 'integral component of plasma membrane' and 'postsynaptic density' (Table II). In addition, the MF of upregulated DEGs were enriched in 'protein binding', 'poly(A) RNA binding' and 'cadherin binding involved in cell-cell adhesion' (Table I), whereas the downregulated DEGs were enriched in 'protein binding', 'epidermal growth factor receptor binding' and 'amino acid transmembrane transfer activity' (Table II). These results suggest that the DEGs were associated with the biological processes of cell migration and metastasis.

KEGG pathway analysis of MIM and MAM DEGs. To further analysis the functions of DEGs, KEGG pathway analysis was conducted to determine the most significantly enriched pathways of the upregulated DEGs and downregulated DEGs. The upregulated DEGs were enriched in 'protein processing in the endoplasmic reticulum', 'antigen processing and presentation' and 'phagosome' pathways (Table III). The downregulated DEGs were enriched in the 'arrhythmogenic right ventricular cardiomyopathy', 'phosphatidylinositol signaling system' and 'inositol phosphate metabolism' pathways (Table III).

Analysis of the PPI network with DEGs in MIM and MAM. According to the information provided by the STRING, the interaction of the DEGs and acquired hub genes of potential diagnosis and treatment associated DEGs were analyzed. As depicted in Figs. 2A and S1, there were 955 nodes and 7,589 edges, of which 638 nodes represented upregulated DEGs and nodes represented downregulated DEGs (Fig. 2B). The top 10 hub genes with the highest degrees included: Heat shock protein family A member 8 (HSPA8); PH domain and leucine rich repeat protein phosphatase 1 (PHLPP1); phosphoribosylglycinamide formyltransferase (GART); carbamoyl-phosphate synthetase $2(\mathrm{CAD})$; actin beta (ACTB); cadherin 1 (CDH1); phosphatidylinositol-4,5-bisphosphate 3-kinase catalytic subunit $\gamma$ (PIK3CG); nuclear factor $\kappa \mathrm{B}$ subunit $1(\mathrm{NF} \kappa \mathrm{B} 1)$; signal transducer and activator of transcription 3 (STAT3); and heat shock protein family A (Hsp70) member 5 (HSPA5). Then, the expression of the top 10 hub genes were verified using RT-qPCR. There were 4 hub upregulated genes and 6 downregulated genes in MAM, compared with MIM samples (Fig. 3). Moreover, the top 3 significant modules were selected from the DEG PPI network using MCODE (Fig. 4A-C). Module 1 included 31 nodes and 458 edges, module 2 included 37 nodes and 267 edges and module 3 included 45 nodes. Furthermore, 
Table I. Gene ontology analysis of upregulated differentially expressed genes associated with metastasis-inclined microenvironment and metastasis-averse microenvironment.

\begin{tabular}{|c|c|c|c|c|}
\hline Category & Term & Gene function & Gene count & P-value \\
\hline $\mathrm{BP}$ & GO:0098609 & Cell-cell adhesion & 37 & $2.9 \times 10^{-10}$ \\
\hline BP & GO:0000398 & mRNA splicing, via spliceosome & 28 & $3.1 \times 10^{-7}$ \\
\hline $\mathrm{BP}$ & GO:0002576 & Platelet degranulation & 18 & $7.1 \times 10^{-7}$ \\
\hline BP & GO:0006457 & Protein folding & 22 & $1.2 \times 10^{-5}$ \\
\hline BP & GO:0048013 & Ephrin receptor signaling pathway & 14 & $3.8 \times 10^{-5}$ \\
\hline $\mathrm{BP}$ & GO:0043066 & Movement of cell or subcellular component & 14 & $3.8 \times 10^{-5}$ \\
\hline BP & GO:0043066 & Negative regulation of apoptotic process & 38 & $4.2 \times 10^{-5}$ \\
\hline BP & GO:0007165 & Signal transduction & 75 & $5.4 \times 10^{-5}$ \\
\hline BP & GO:0019886 & $\begin{array}{l}\text { Antigen processing and presentation of } \\
\text { exogenous peptide antigen via MHC class II }\end{array}$ & 14 & $7.8 \times 10^{-5}$ \\
\hline BP & GO:0050900 & Leukocyte migration & 16 & $1.1 \times 10^{-4}$ \\
\hline $\mathrm{CC}$ & GO:0070062 & Extracellular exosome & 220 & $1.1 \times 10^{-28}$ \\
\hline $\mathrm{CC}$ & GO:0016020 & Membrane & 170 & $7.6 \times 10^{-21}$ \\
\hline $\mathrm{CC}$ & GO:0005829 & Cytosol & 218 & $1.4 \times 10^{-18}$ \\
\hline $\mathrm{CC}$ & GO:0005654 & Nucleoplasm & 177 & $4.2 \times 10^{-13}$ \\
\hline $\mathrm{CC}$ & GO:0005913 & Cell-cell adherens junction & 44 & $5.2 \times 10^{-13}$ \\
\hline $\mathrm{CC}$ & GO:0031012 & Extracellular matrix & 37 & $5.5 \times 10^{-10}$ \\
\hline $\mathrm{CC}$ & GO:0042470 & Melanosome & 21 & $9.2 \times 10^{-10}$ \\
\hline $\mathrm{CC}$ & GO:0043209 & Myelin sheath & 25 & $2.5 \times 10^{-9}$ \\
\hline $\mathrm{CC}$ & GO:0005615 & Extracellular space & 90 & $1.1 \times 10^{-7}$ \\
\hline $\mathrm{CC}$ & GO:0030529 & Intracellular ribonucleoprotein complex & 21 & $1.8 \times 10^{-7}$ \\
\hline MF & GO:0005515 & Protein binding & 448 & $2.8 \times 10^{-14}$ \\
\hline MF & GO:0044822 & Poly(A) RNA binding & 100 & $7.6 \times 10^{-14}$ \\
\hline MF & GO:0098641 & Cadherin binding involved in cell-cell adhesion & 42 & $1.8 \times 10^{-12}$ \\
\hline MF & GO:0032403 & Protein complex binding & 23 & $2.8 \times 10^{-5}$ \\
\hline MF & GO:0003723 & RNA binding & 43 & $4.3 \times 10^{-5}$ \\
\hline MF & GO:0051287 & NAD binding & 9 & $1.1 \times 10^{-4}$ \\
\hline MF & GO:0051082 & Unfolded protein binding & 15 & $1.3 \times 10^{-4}$ \\
\hline MF & GO:0008134 & Transcription factor binding & 25 & $4.8 \times 10^{-4}$ \\
\hline MF & GO:0005524 & ATP binding & 86 & $5.9 \times 10^{-4}$ \\
\hline MF & GO:0019899 & Enzyme binding & 27 & $9.6 \times 10^{-4}$ \\
\hline
\end{tabular}

$\mathrm{P}<0.001$. GO, Gene Ontology; BP, biological process; CC, cellular component; MF, molecular function.

GO and KEGG pathway analysis results were used to analyze the functional and signal pathway enrichment of the three modules. The results showed that module 1 was primarily associated with 'RNA splicing', 'catalytic step 2 spliceosome', 'nucleotide binding' and 'spliceosome' pathways (Table IV). Module 2 was primarily enriched in 'protein modification by small protein conjugation', 'catalytic complex', 'ubiquitin-protein transferase activity' and 'chemokine signaling' pathways (Table V). Module 3 was most enriched in 'protein folding,' 'extracellular exosomes', 'protein disulfide isomerase activity' and 'chemokine signaling' pathways (Table VI). These results indicated that the 10 hub genes may function in the biological behavior processes of cell migration and metastasis.

The Kaplan-Meier plot of hub genes in MIM and MAM. Through GEPIA prediction of the association between the
10 hub genes and HCC patient prognosis, it was observed that expression of CAD [Hazard Ratio (HR), 1.9; $\mathrm{P}<0.001$ ], GART (HR, 1.8; P=0.018), HSPA5 (HR, 1.5; $\mathrm{P}=0.016)$, ACTB (HR, 1.6; $\mathrm{P}=0.0074), \mathrm{CDH} 1$ (HR, 0.66; $\mathrm{P}=0.018)$ and HSPA8 (HR, 1.6; $\mathrm{P}=0.011)$ were associated with poor overall survival in patients with HCC (Fig. 5).

\section{Discussion}

$\mathrm{HCC}$ is the most common malignant tumor with high morbidity and mortality, and was reported to be one of the major causes of cancer-associated mortalities worldwide, in 2002 (13). Patients with HCC are often diagnosed with extrahepatic metastasis, which poses a great challenge to the diagnosis and treatment of HCC (14). Currently, high-throughput gene chip technology can be used to explore the occurrence and development of diseases from the whole genome or transcriptome 
Table II. Gene ontology analysis of downregulated differentially expressed genes associated with metastasis-inclined microenvironment and metastasis-averse microenvironment.

\begin{tabular}{|c|c|c|c|c|}
\hline Category & Term & Gene function & Gene count & P-value \\
\hline $\mathrm{BP}$ & GO:0007155 & Cell adhesion & 28 & ${ }^{c} 2.8 \times 10^{-5}$ \\
\hline $\mathrm{BP}$ & GO:0008283 & Cell proliferation & 22 & ${ }^{c} 3.0 \times 10^{-4}$ \\
\hline $\mathrm{BP}$ & GO:0042523 & $\begin{array}{l}\text { Positive regulation of tyrosine phosphorylation } \\
\text { of Stat5 protein }\end{array}$ & 5 & ${ }^{\mathrm{c}} 6.7 \times 10^{-4}$ \\
\hline $\mathrm{BP}$ & GO:0007165 & Signal transduction & 47 & ${ }^{c} 9.4 \times 10^{-4}$ \\
\hline $\mathrm{BP}$ & GO:0031532 & Actin cytoskeleton reorganization & 6 & b5 $8 \times 10^{-3}$ \\
\hline $\mathrm{BP}$ & GO:0009267 & Cellular response to starvation & 6 & b5 $8 \times 10^{-3}$ \\
\hline $\mathrm{BP}$ & GO:0060749 & Mammary gland alveolus development & 4 & b7.8x $10^{-3}$ \\
\hline $\mathrm{BP}$ & GO:0007169 & $\begin{array}{l}\text { Transmembrane receptor protein tyrosine } \\
\text { kinase signaling pathway }\end{array}$ & 8 & b9.5 $910^{-3}$ \\
\hline $\mathrm{BP}$ & GO:0006865 & Amino acid transport & 5 & b $1.0 \times 10^{-2}$ \\
\hline $\mathrm{BP}$ & GO:0045944 & $\begin{array}{l}\text { Positive regulation of transcription from RNA } \\
\text { polymerase II promoter }\end{array}$ & 37 & ${ }^{\mathrm{a}} 1.1 \times 10^{-2}$ \\
\hline $\mathrm{CC}$ & GO:0043235 & Receptor complex & 90 & ${ }^{\mathrm{c}} 1.9 \times 10^{-4}$ \\
\hline $\mathrm{CC}$ & GO:0005887 & Integral component of plasma membrane & 47 & ${ }^{\mathrm{c}} 4.1 \times 10^{-4}$ \\
\hline $\mathrm{CC}$ & GO:0014069 & Postsynaptic density & 78 & ${ }^{\mathrm{b}} 1.3 \times 10^{-3}$ \\
\hline $\mathrm{CC}$ & GO:0045211 & Postsynaptic membrane & 64 & b $1.4 \times 10^{-3}$ \\
\hline $\mathrm{CC}$ & GO:0005829 & Cytosol & 52 & ${ }^{b} 2.1 \times 10^{-3}$ \\
\hline $\mathrm{CC}$ & GO:0005886 & Plasma membrane & 52 & b3.6x $10^{-3}$ \\
\hline $\mathrm{CC}$ & GO:0009986 & Cell surface & 52 & $\mathrm{~b} 4.5 \times 10^{-3}$ \\
\hline $\mathrm{CC}$ & GO:0030054 & Cell junction & 15 & b5 $8 \times 10^{-3}$ \\
\hline $\mathrm{CC}$ & GO:0005794 & Golgi apparatus & 8 & ${ }^{\mathrm{b}} 6.7 \times 10^{-3}$ \\
\hline $\mathrm{CC}$ & GO:0005737 & Cytoplasm & 8 & b7 $7.5 \times 10^{-3}$ \\
\hline MF & GO:0005515 & Protein binding & 258 & ${ }^{\mathrm{c}} 1.5 \times 10^{-5}$ \\
\hline $\mathrm{MF}$ & GO:0005154 & Epidermal growth factor receptor binding & 6 & ${ }^{c} 8.6 \times 10^{-4}$ \\
\hline $\mathrm{MF}$ & GO:0015171 & Amino acid transmembrane transporter activity & 7 & c8.6x $10^{-4}$ \\
\hline $\mathrm{MF}$ & GO:0005524 & ATP binding & 56 & ${ }^{c} 9.5 \times 10^{-4}$ \\
\hline MF & GO:0042803 & Protein homodimerization activity & 32 & ${ }^{\mathrm{b}} 1.5 \times 10^{-3}$ \\
\hline MF & GO:0004714 & $\begin{array}{l}\text { Transmembrane receptor protein tyrosine } \\
\text { kinase activity }\end{array}$ & 6 & ${ }^{b} 2.1 \times 10^{-3}$ \\
\hline $\mathrm{MF}$ & GO:0008179 & Adenylate cyclase binding & 3 & ${ }^{\mathrm{a}} 1.9 \times 10^{-2}$ \\
\hline MF & GO:0001078 & $\begin{array}{l}\text { Transcriptional repressor activity, RNA } \\
\text { polymerase II core promoter proximal region } \\
\text { sequence-specific binding }\end{array}$ & 8 & ${ }^{\mathrm{a}} 1.9 \times 10^{-2}$ \\
\hline $\mathrm{MF}$ & GO:0005096 & Gtpase activator activity & 14 & $2.0 \times 10^{-2}$ \\
\hline MF & GO:0043236 & Laminin binding promoter & 4 & $2.2 \times 10^{-2}$ \\
\hline
\end{tabular}

${ }^{\mathrm{a}} \mathrm{P}<0.05,{ }^{\mathrm{b}} \mathrm{P}<0.01,{ }^{\mathrm{c}} \mathrm{P}<0.001$. GO, Gene Ontology; BP, biological process; CC, cellular component; MF, molecular function.

level, which has been widely used in gene expression analysis and biomarker discovery for a variety of illnesses (14). In order to further understand the molecular mechanisms underlying the recurrence and metastasis of HCC, the GSE5093 Biochip dataset on the metastatic microenvironment of HCC was obtained from the GEO database. This was used to perform a systematic and bioinformatics analysis, including enrichment analysis of differences in gene expression and protein-protein interaction.

In the present study, a total of 1,171 DEGs were identified, of which 712 were upregulated and 459 were downregulated. GO term functional analysis demonstrated that the upregulated genes were primarily involved in 'cell-cell adhesion', 'extracellular exosome' and 'cadherin binding', while downregulated DEGs were involved in 'cell-cell adhesion', 'integral component of plasma membrane' and 'epidermal growth factor receptor binding'. The tumor cells leave the primary site, invade the extracellular matrix, adhere to macromolecular protein components in the basement membrane, degrade the basement membrane and the extracellular matrix, and move through the extracellular matrix to invade the surrounding tissues (15). Once in the circulation system, tumor cells evade the surveillance of the immune system. When passing through the vessel wall to 


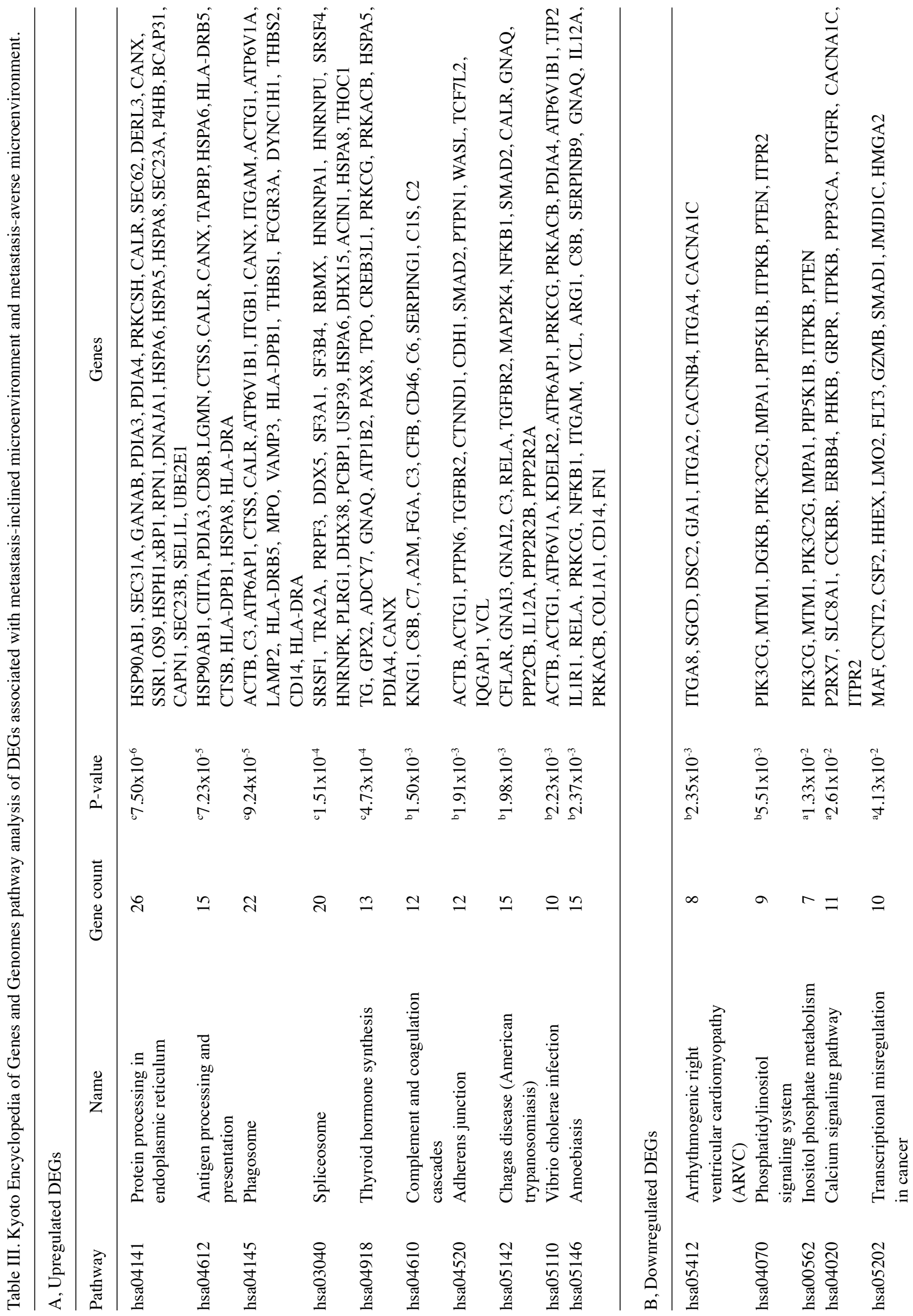


the secondary site, tumor cells adhere to the secondary site, proliferate and eventually metastasize $(16,17)$. Cell adhesion, receptor complex, integral component of plasma membrane, postsynaptic density and epidermal growth factor receptor binding are key auxiliary components (18-20). Cell adhesion molecules suppress the adhesive function of tumor cells and glycoproteins located on the cell surface (21). Moreover, KEGG pathway analysis indicated that the upregulated DEGs influenced 'protein processing in endoplasmic reticulum', 'antigen processing and presentation' and 'phagosome'; the downregulated DEGs were associated with 'arrhythmogenic right ventricular cardiomyopathy', 'phosphatidylinositol signaling system' and 'inositol phosphate metabolism'. Tumor metastasis involves detachment from the primary site of the tumor, entrance into the surrounding stroma and the circulation or lymphatic system, adhesion to endothelial cell walls, extravasation and invasion through vascular proliferation for the formation a novel metastatic lesion $(22,23)$. GO and KEGG analyses suggested that the aforementioned DEGs may influence signaling pathways associated with tumor cell metastasis. The identified DEGs may provide novel research directions and targets for the treatment of HCC metastasis.

Based on the established PPI network with DEGs, the following top 10 hub genes were identified: HSPA8, PHLPP1, GART, CAD, ACTB, CDH1, PIK3CG, NFאB1, STAT3 and HSPA5. HSPA8 is a member of the heat shock proteins family, which influences molecular signal transduction, apoptosis and protein regulation (24). HSPA8 is located in the cytoplasm and lysosomes and is involved in mediating cell autophagy by binding to the substrate protein and transporting it into the lysosomal cavity $(25,26)$. Novel research has shown that the Hsp70 protein may inhibit apoptosis by regulating the caspase-dependent pathway (27). Moreover, tumor vaccines against HSP70S have been successfully completed in animal models and clinical trials are underway (27).

PHLPP1 is an important regulator of Akt serine-threonine kinases and conventional/novel protein kinase $\mathrm{C}$ isoforms (28). PHLPP1 can inhibit growth factor-induced signal transduction pathways in cancer cells, so it may be used as a growth inhibitor in several types of cancer (28). In the human breast cancer cell line 21T, AK294 phosphorylation was inhibited by LY294002, and the expression of PHLPP1 in two metastatic cell lines (MT1 and MT2) was much lower compared with early breast cancer cells (29). PHLPP1 can negatively regulate the activity of AKT and its downstream kinase by phosphorylating the hydrophobic group of AKT at the Serine 473 site. This resulted in inhibition of the PI3K/AKT signaling pathway, and the activation of various cancer promoting signaling pathways, including amplification or gain-of-function mutations in upstream receptor protein tyrosine kinases (RPTKs), activating mutations in PI3K and Akt and loss-of-function mutations in the regulatory phosphatase PTEN, which affect differentiation and proliferation of cancer cells and apoptosis in breast cancer cells (29). Therefore, it is hypothesized that PHLPP1 is associated with tumor metastasis.

Trifunctional purine biosynthetic protein adenosine-3 is an enzyme that is encoded by the GART gene (30). GART participates in several aspects of energy metabolism, including as a ATP binding source, metal ion 

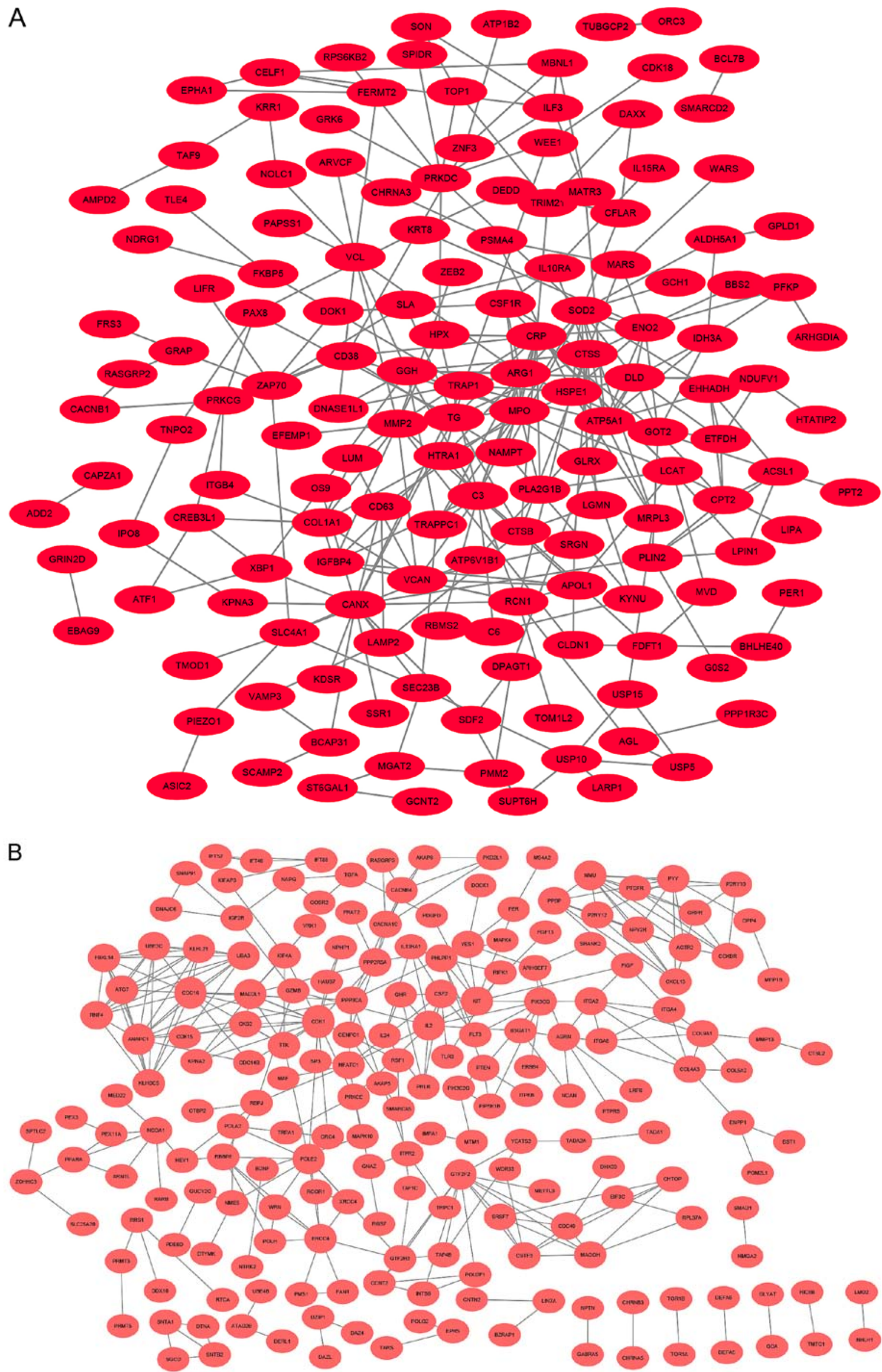

Figure 2. DEG protein-protein interaction network in metastasis-inclined microenvironment and metastasis-averse microenvironment. (A) The most significant interaction network of the upregulated DEGs interaction network. (B) Interaction network of the 317 downregulated DEGs interaction network. DEG, differentially expressed gene. 

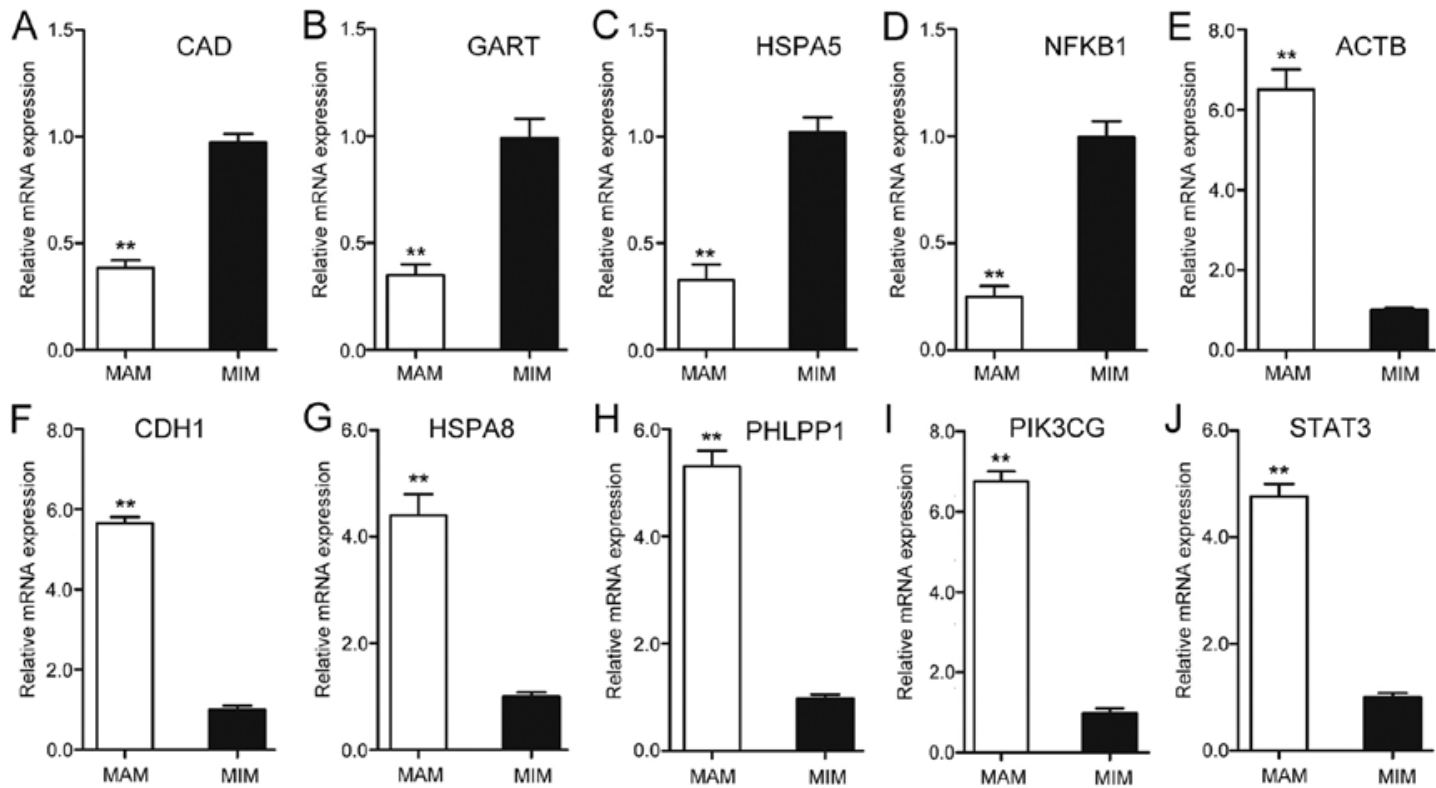

Figure 3. Top 10 hub genes were detected by reverse transcription-quantitative PCR. Expression of (A) CAD, (B) GART, (C) HSPA5, (D) NFKB1, (E) ACTB, (F) CDH1, (G) HSPA8, (H) PHLPP1, (I) PIK3GC and (J) STAT3 The data are presented as the mean \pm standard deviation of 3 independent experiments. ${ }^{* *} \mathrm{P}<0.01$ MAM vs. MIM. CAD, carbamoyl-phosphate synthetase 2; GART, phosphoribosylglycinamide formyltransferase; HSPA5, heat shock protein family A member 5; NFkB1, nuclear factor $\kappa$ B subunit 1; ACTB, actin beta; CDH1, Cadherin 1; HSPA8, heat shock protein family A member 8; PHLPP1, PH domain and leucine rich repeat protein phosphatase 1; PIK3CG, phosphatidylinositol-4,5-bisphosphate 3-kinase catalytic subunit $\gamma$; STAT3, signal transducer and activator of transcription 3 .

binding source and phosphoribosylamine-glycine ligase activity source $(30,31)$. CAD is a fusion gene that encodes three enzymes involved in pyrimidine biosynthesis; carbamoyl-phosphate synthetase 2 and aspartate transcarbamylase fused with dihydroorotase (31). CAD is a key enzyme the regulates multiple biological processes in the first three steps of pyrimidine biosynthesis (32). These three genes serve a role in the synthesis and metabolism of nucleic acids and proteins in cells, and their synthesized products provide essential substances and energy for cell proliferation (32).

Actin is a major constituent of the muscular contractile apparatus and ACTB is one of six different actin isoforms that have been identified in humans (33). ACTB binds RNA-binding protein Sam68 and participates in the regulation of the synaptic formation of dendritic spines (34). ACTB supports the muscular cytoskeleton during the formation of novel tumor cells following tumor cell proliferation and metastasis. Thus, ACTB is considered to be associated with cell proliferation and metastasis (34).

CDH1, also known as epithelial cadherin (E-cadherin), is a protein encoded by the CDH1 gene (35). Mutations in $\mathrm{CDH} 1$ are closely associated with liver, colorectal and gastric cancer. Moreover, a functional deficit of CDH1 promotes the proliferation and invasiveness of tumor cells, and promotes the malignant development of tumors (35). E-cadherin is a member of the cadherin family and downregulation of E-cadherin reduces cell-cell adhesion, which results in cells that are more susceptible to migration (36). This change can easily result in cancer cells passing through the cell basement membrane and invading surrounding tissues (36). A previous study demonstrated that E-cadherin is an important protein that regulates cell-cell adhesion. On the cell membrane, E-cadherin binds to $\beta$-catenin via its cytoplasmic tail, allowing epithelial cells to bind tightly together.
Knockdown of E-cadherin expression results in $\beta$-catenin release into the cytoplasm and translocation into the nucleus, and this process can result in the expression of epithelial mesenchymal transition (EMT)-inducible transcription factors. Therefore, E-cadherin is an important gene that regulates EMT (37).

The PIK3CG subunit $\lambda$ isoform is an enzyme encoded by the PIK3CG gene (38). Several studies have demonstrated that the function of PIK3CG is to regulate the transmission of extracellular signals, including E-cadherin-mediated cell-cell adhesion, which serves an important role in maintaining the structural and functional integrity of the epithelium $(39,40)$.

The NFאB1 gene is a cellular transcription factor and encodes the NF- $\mathrm{BB}$ p105 subunit protein. The expression of $\mathrm{NF}-\kappa \mathrm{B}$ is activated via various stimuli, such as cytokines, oxidative free radicals and bacterial or viral products (41). Activated $N F-\kappa B$ is transported to the nucleus to participate in the transcription and synthesis of various proteins and signaling molecules, regulating various cell behaviors (41). It has been revealed that osteopontin can regulate the expression of MTI-MMP via the NF- $\mathrm{BB}$ signaling pathway and promote the migration of cancer cells and invasion into the extracellular matrix (42). A previous study confirmed that several adhesion molecules, such as ICAM-1, VCAM-1 and ELAM-1, are regulated by $\mathrm{NF}-\kappa \mathrm{B}$, which serves an important role in tumor metastasis (43).

STAT3, which contains SH2 and SH3 domains, binds to specific phosphotyrosine-containing peptides. When STAT3 is activated by phosphorylation, it serves as a transcriptional activator, in either its homodimeric or heterodimeric form (44). Phosphorylated STAT3 binds a specific site in the target gene promoter sequence and promotes transcription of the gene (44). Dysregulation of this pathway in tumors leads 


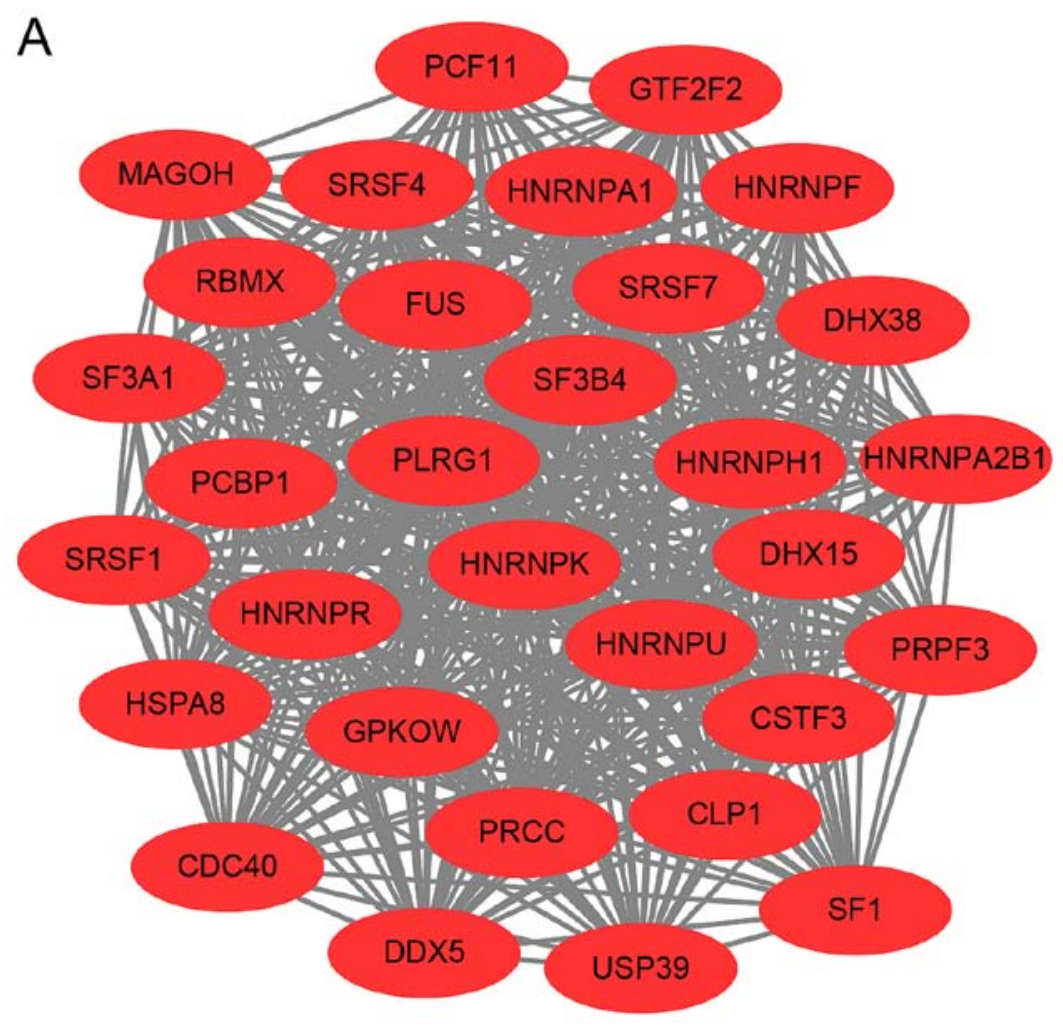

B

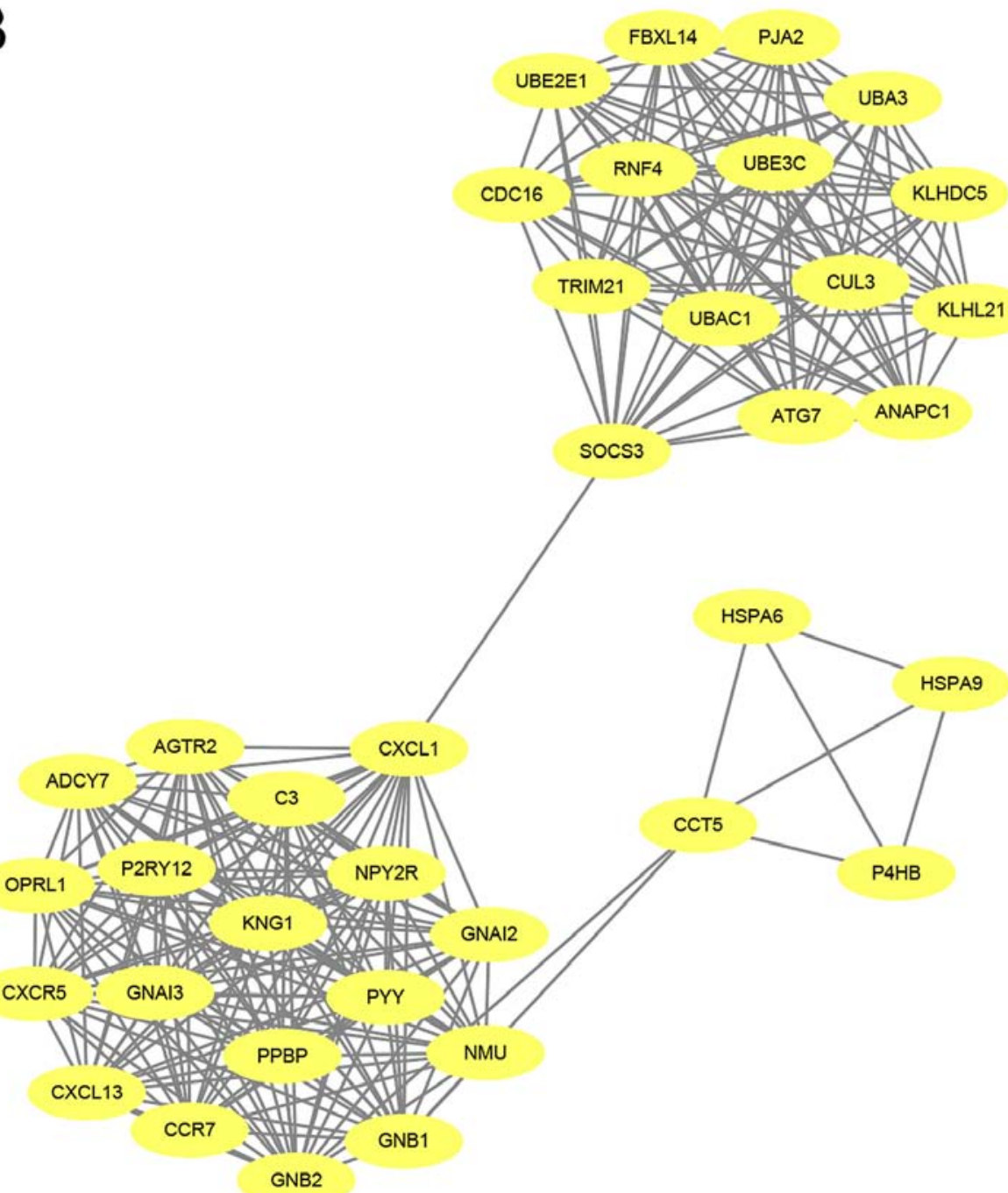

Figure 4. Top 3 modules from the protein-protein interaction network determined by the molecular complex detection score. (A) Module 1 and (B) Module 2. 


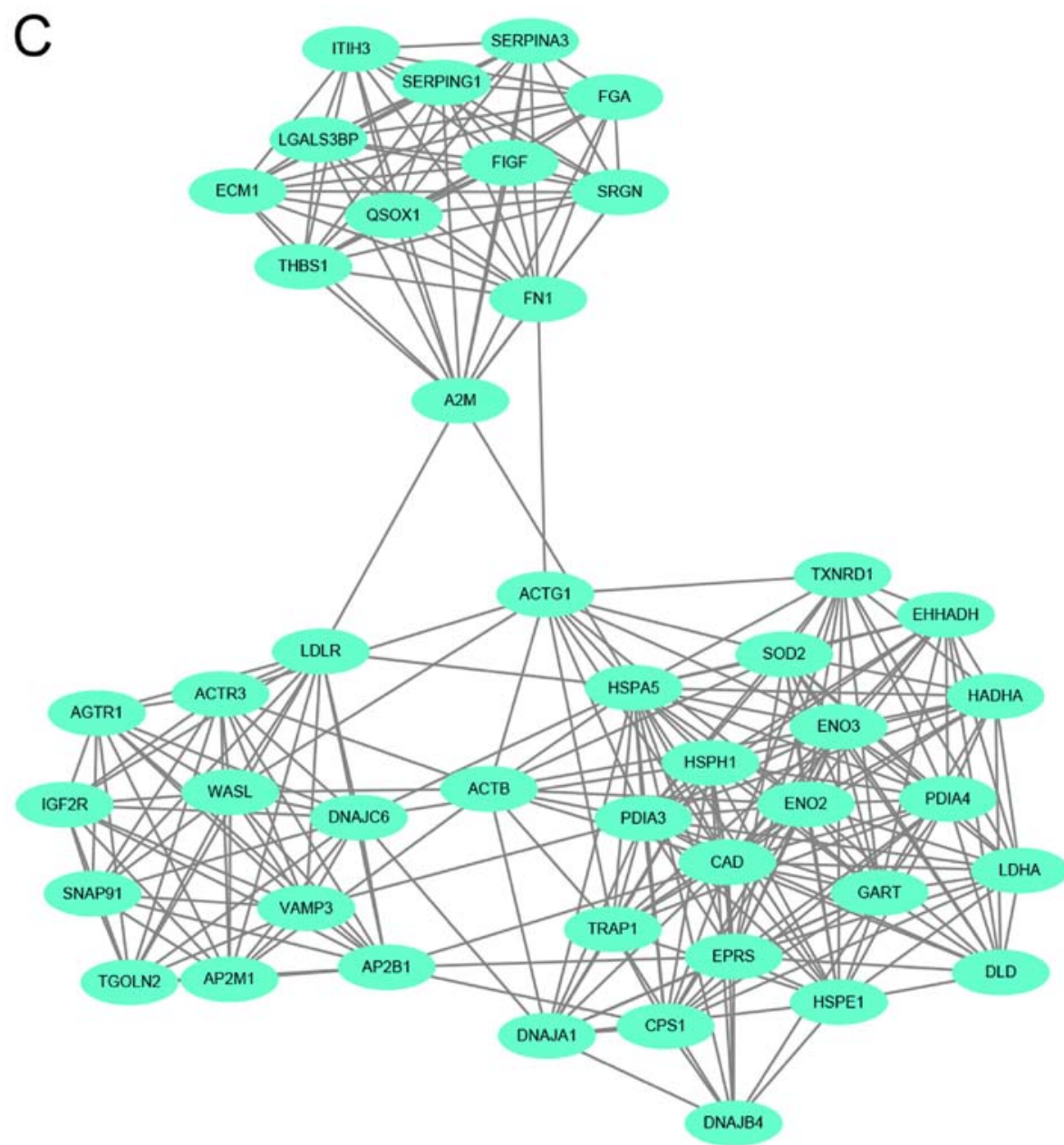

Figure 4. Continued. Top 3 modules from the protein-protein interaction network determined by the molecular complex detection score. (C) Module 3.

Table IV. Functional and pathway enrichment analysis of the genes in module 1.

\begin{tabular}{|c|c|c|c|c|}
\hline Category & Term & Gene function & Gene count & P-value \\
\hline $\mathrm{BP}$ & GO:0008380 & RNA splicing & 6 & ${ }^{c} 2.27 \times 10^{-9}$ \\
\hline BP & GO: 0000398 & mRNA splicing, via spliceosome & 6 & $8.01 \times 10^{-7}$ \\
\hline BP & GO:0006397 & mRNA processing & 5 & ${ }^{c} 2.06 \times 10^{-6}$ \\
\hline BP & GO:0048025 & Negative regulation of mRNA splicing, via spliceosome & 4 & ${ }^{c} 3.81 \times 10^{-6}$ \\
\hline BP & GO:0000381 & Regulation of alternative mRNA splicing, via spliceosome & 4 & ${ }^{\mathrm{c}} 4.06 \times 10^{-5}$ \\
\hline $\mathrm{CC}$ & GO:0071013 & Catalytic step 2 spliceosome & 3 & ${ }^{\mathrm{c}} 6.60 \times 10^{-19}$ \\
\hline $\mathrm{CC}$ & GO:0005681 & Spliceosomal complex & 2 & ${ }^{\mathrm{c}} 1.58 \times 10^{-10}$ \\
\hline $\mathrm{CC}$ & GO:0030529 & Intracellular ribonucleoprotein complex & 2 & ${ }^{c} 8.66 \times 10^{-9}$ \\
\hline $\mathrm{CC}$ & GO:0019013 & Viral nucleocapsid & 2 & $\mathrm{c} 7.85 \times 10^{-8}$ \\
\hline $\mathrm{CC}$ & GO:0005654 & Nucleoplasm & 12 & ${ }^{c} 8.50 \times 10^{-6}$ \\
\hline MF & GO:0000166 & Nucleotide binding & 7 & ${ }^{c} 3.01 \times 10^{-10}$ \\
\hline MF & GO:0044822 & Poly(A) RNA binding & 7 & ${ }^{\mathrm{c}} 1.66 \times 10^{-9}$ \\
\hline MF & GO:0003723 & RNA binding & 6 & ${ }^{\mathrm{c}} 1.95 \times 10^{-5}$ \\
\hline MF & GO:0003729 & mRNA binding & 12 & $4.65 \times 10^{-5}$ \\
\hline MF & GO:0003676 & Nucleic acid binding & 7 & ${ }^{c} 8.67 \times 10^{-4}$ \\
\hline KEGG_PATHWAY & has:03040 & Spliceosome & 20 & ${ }^{\mathrm{c}} 1.54 \times 10^{-28}$ \\
\hline KEGG_PATHWAY & has: 03015 & mRNA surveillance pathway & 4 & $\mathrm{~b} 4.32 \times 10^{-3}$ \\
\hline KEGG_PATHWAY & has: 05168 & Herpes simplex infection & 4 & a $3.18 \times 10^{-2}$ \\
\hline
\end{tabular}

${ }^{\mathrm{a}} \mathrm{P}<0.05,{ }^{\mathrm{b}} \mathrm{P}<0.01,{ }^{\mathrm{c}} \mathrm{P}<0.001$. GO, Gene Ontology; BP, biological process; CC, cellular component; MF, molecular function; KEGG, Kyoto Encyclopedia of Genes and Genomes. 
A

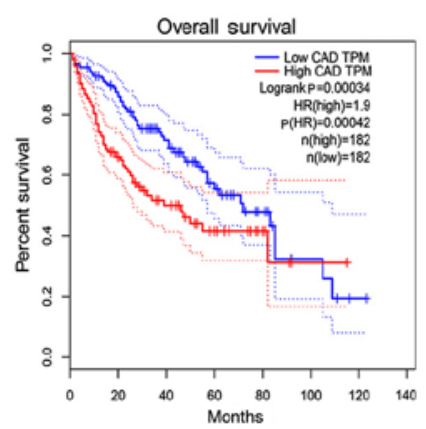

E

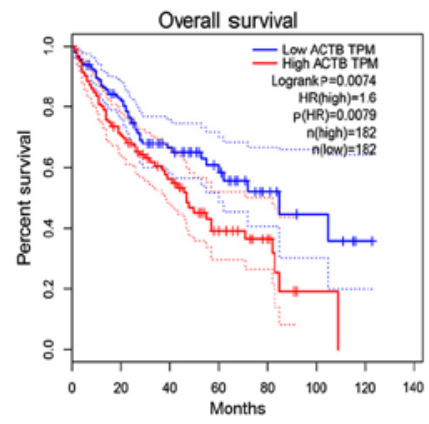

B

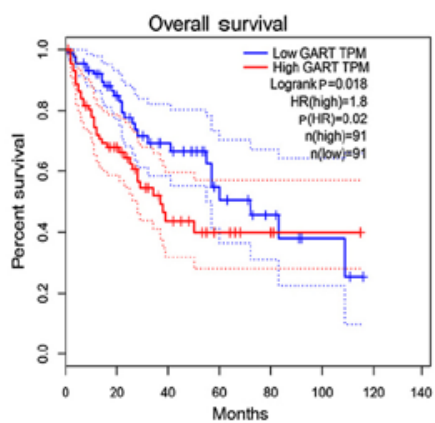

F

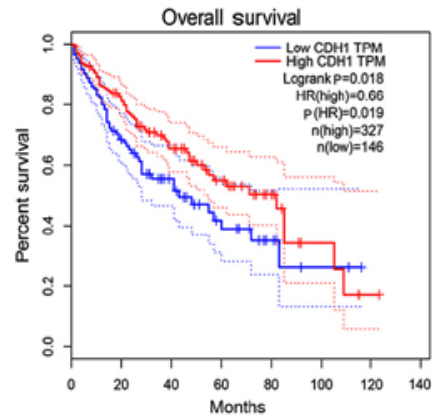

C

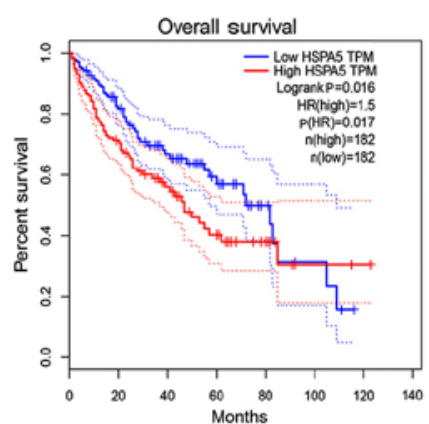

G

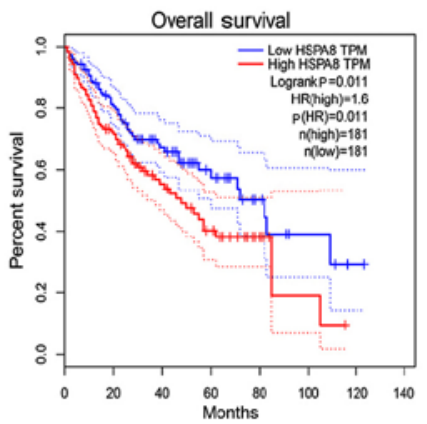

D

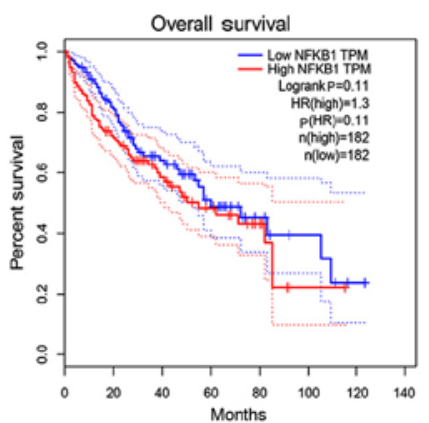

$\mathrm{H}$

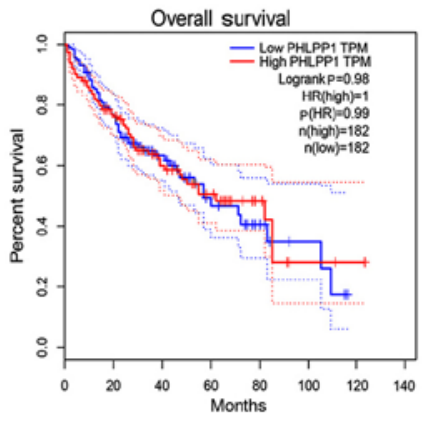

I

J
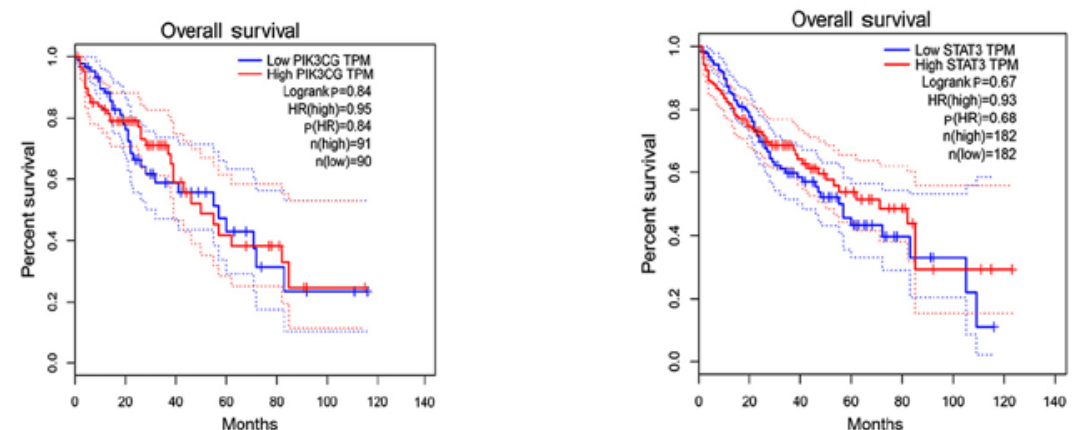

Figure 5. Prognostic value of hub genes in patients with HCC. Kaplan-Meier analysis of OS time un patients with HCC with high and low expression levels of: (A) CAD, (B) GART, (C) HSPA5, (D) NFкB1, (E) ACTB, (F) CDH1, (G) HSPA8, (H) PHLPP1, (I) PIK3CG and (J) STAT3. The red dotted line above the red curve and the red dotted line below represent the high $(50 \%)$ and low cutoff $(50 \%)$ on the survival curve. The blue dotted line above the blue curve and the blue dotted line below represent high (50\%) and low cutoff (50\%) on the survival curve. HCC, hepatocellular carcinoma; OS, overall survival; CAD, carbamoyl-phosphate synthetase 2; GART, phosphoribosylglycinamide formyltransferase; HSPA5, heat shock protein family A member 5; NFKB1, nuclear factor $\kappa \mathrm{B}$ subunit 1 ; ACTB, actin beta; $\mathrm{CDH} 1$, cadherin 1; HSPA8, heat shock protein family A member 8; PHLPP1, PH domain and leucine rich repeat protein phosphatase 1; PIK3CG, phosphatidylinositol-4,5-bisphosphate 3-kinase catalytic subunit $\gamma$; STAT3, signal transducer and activator of transcription 3; HR, hazard ratio; TPM, transcripts per million.

to increased angiogenesis surrounding the tumor, promotes blood supply to the tumor, increases tumor survival and promotes malignant development. It has been demonstrated that tissue-specific inactivation of STAT3 in the lungs of mice is associated with the occurrence and progression of lung adenocarcinoma, which reduced the survival rate. Notably, decreased expression of STAT3 promotes the expression of $\mathrm{NF}-\kappa \mathrm{B}$ in the cytoplasm, thus regulating NF- $\kappa \mathrm{B}$-induced IL-8 expression (45). This process promotes IL-8-mediated tumor invasion, angiogenesis and progression (45).

Binding immunoglobulin protein, also known as HSPA5, is a protein that is encoded by the HSPA5 gene (46). A large number of studies have revealed the high expression of HSPA5 in all malignant tumors $(47,48)$. Therefore, inhibiting HSPA5 gene expression may be used as an adjuvant therapy for cancer. In addition, reducing the large amount of HSPA 5 produced during the stress response can increase the apoptosis of tumor cells and inhibit tumor growth (49).

In addition, tumor metastasis is a complex multi-step process, whereby tumor cells not only interact with each other and host cells, but also with extracellular matrix components (50). Certain characteristics, such as adhesion, metastasis, migration, skeleton assembly, signal transduction and proliferation are associated with tumor metastasis $(50,51)$. Migration is considered a key factor in the process of tumor cell metastasis (51). Previous studies have demonstrated 
Table V. Functional and pathway enrichment analysis of the genes in module 2.

\begin{tabular}{|c|c|c|c|c|}
\hline Category & Term & Gene function & Gene count & P-value \\
\hline $\mathrm{BP}$ & GO:0032446 & Protein modification by small protein conjugation & 12 & b $6.57 \times 10^{-9}$ \\
\hline $\mathrm{BP}$ & GO:0070647 & $\begin{array}{l}\text { Protein modification by small protein conjugation or } \\
\text { removal }\end{array}$ & 12 & b5 $5.38 \times 10^{-8}$ \\
\hline $\mathrm{BP}$ & GO:0007186 & G-protein coupled receptor signaling pathway & 11 & b $2.93 \times 10^{-7}$ \\
\hline $\mathrm{BP}$ & GO:0016567 & Protein ubiquitination & 10 & b5 $5.90 \times 10^{-7}$ \\
\hline $\mathrm{BP}$ & GO:0007193 & $\begin{array}{l}\text { Adenylate cyclase-inhibiting G-protein coupled receptor } \\
\text { signaling pathway }\end{array}$ & 5 & b $6.02 \times 10^{-6}$ \\
\hline $\mathrm{CC}$ & GO:1902494 & Catalytic complex & 11 & b9.45 $910^{-6}$ \\
\hline $\mathrm{CC}$ & GO:0000151 & Ubiquitin ligase complex & 7 & b $1.07 \times 10^{-5}$ \\
\hline $\mathrm{CC}$ & GO:0098552 & Side of membrane & 5 & b2.94x $10^{-4}$ \\
\hline $\mathrm{CC}$ & GO:1990234 & Transferase complex & 6 & b3.96x $10^{-4}$ \\
\hline $\mathrm{CC}$ & GO:0000152 & Nuclear ubiquitin ligase complex & 3 & ${ }^{\mathrm{a}} 1.53 \times 10^{-3}$ \\
\hline MF & GO:0004842 & Ubiquitin-protein transferase activity & 8 & b3.79 $310^{-6}$ \\
\hline MF & GO:0001664 & G-protein coupled receptor binding & 6 & b $4.47 \times 10^{-6}$ \\
\hline MF & GO:0019787 & Ubiquitin-like protein transferase activity & 8 & b $5.20 \times 10^{-6}$ \\
\hline MF & GO:0008528 & G-protein coupled peptide receptor activity & 5 & b $1.42 \times 10^{-4}$ \\
\hline MF & GO:0001653 & Peptide receptor activity & 5 & ${ }^{\mathrm{b}} 1.52 \times 10^{-4}$ \\
\hline KEGG_PATHWAY & has: 04062 & Chemokine signaling pathway & 11 & $\mathrm{~b} 4.43 \times 10^{-10}$ \\
\hline KEGG_PATHWAY & has: 04120 & Ubiquitin mediated proteolysis & 6 & b $1.26 \times 10^{-4}$ \\
\hline KEGG_PATHWAY & has: 04914 & Progesterone-mediated oocyte maturation & 5 & b $2.19 \times 10^{-4}$ \\
\hline
\end{tabular}

${ }^{\mathrm{a}} \mathrm{P}<0.01,{ }^{\mathrm{b}} \mathrm{P}<0.001$. GO, gene ontology; BP, biological process; $\mathrm{CC}$, cellular component; MF, molecular function; KEGG, Kyoto Encyclopedia of Genes and Genomes.

Table VI. Functional and pathway enrichment analysis of the genes in module 3.

\begin{tabular}{|c|c|c|c|c|}
\hline Category & Term & Gene function & Gene count & P-value \\
\hline $\mathrm{BP}$ & GO:0006457 & Protein folding & 8 & b $1.45 \times 10^{-7}$ \\
\hline $\mathrm{BP}$ & GO:0045454 & Cell redox homeostasis & 5 & b3.19x $10^{-5}$ \\
\hline $\mathrm{BP}$ & GO:0044710 & Single-organism metabolic process & 19 & b4.36 $310^{-5}$ \\
\hline $\mathrm{BP}$ & GO:0006091 & Generation of precursor metabolites and energy & 6 & b3.46x $10^{-4}$ \\
\hline $\mathrm{BP}$ & GO:0090066 & Regulation of anatomical structure size & 7 & b3.49x $10^{-4}$ \\
\hline $\mathrm{CC}$ & GO:0070062 & Extracellular exosome & 23 & b $1.72 \times 10^{-8}$ \\
\hline $\mathrm{CC}$ & GO:0072562 & Blood microparticle & 5 & b7.56x $10^{-5}$ \\
\hline $\mathrm{CC}$ & GO:0005577 & Fibrinogen complex & 3 & ${ }^{\mathrm{b}} 1.64 \times 10^{-4}$ \\
\hline $\mathrm{CC}$ & GO:0043209 & Myelin sheath & 5 & b5 $5.65 \times 10^{-4}$ \\
\hline $\mathrm{CC}$ & GO:0005829 & Cytosol & 9 & $2.90 \times 10^{-3}$ \\
\hline MF & GO:0003756 & Protein disulfide isomerase activity & 3 & ${ }^{\mathrm{a}} 1.07 \times 10^{-3}$ \\
\hline MF & GO:0005524 & ATP binding & 11 & ${ }^{\mathrm{a}} 1.31 \times 10^{-3}$ \\
\hline MF & GO:0004070 & Aspartate carbamoyltransferase activity & 2 & a $5.77 \times 10^{-3}$ \\
\hline MF & GO:0004088 & $\begin{array}{l}\text { Carbamoyl-phosphatesynthase (glutamine-hydrolyzing) } \\
\text { activity }\end{array}$ & 2 & a $5.77 \times 10^{-3}$ \\
\hline MF & GO:0004087 & Carbon metabolism & 2 & a. $5.77 \times 10^{-3}$ \\
\hline KEGG_PATHWAY & has: 01200 & Chemokine signaling pathway & 5 & ${ }^{\mathrm{a}} 1.23 \times 10^{-3}$ \\
\hline KEGG_PATHWAY & has: 04144 & Endocytosis & 6 & $2.89 \times 10^{-3}$ \\
\hline KEGG_PATHWAY & has: 05100 & Bacterial invasion of epithelial cells & 4 & a $4.33 \times 10^{-3}$ \\
\hline
\end{tabular}

${ }^{\mathrm{a}} \mathrm{P}<0.01,{ }^{\mathrm{b}} \mathrm{P}<0.001$. GO, gene ontology; BP, biological process; $\mathrm{CC}$, cellular component; MF, molecular function; KEGG, Kyoto Encyclopedia of Genes and Genomes. 
that RNA splicing, protein modification by small protein conjugation, catalytic complex, ubiquitin-protein transferase activity, chemokine signaling pathways, protein folding, extracellular exosomes, protein disulfide isomerase activity and chemokine signaling pathways are also involved in the process of tumor cell migration and metastasis, such as the expansion of the cell front, the formation of new adhesion sites and the release of the original adhesion sites in the tail of the cell (52-56).

A study reported that miR-26b-5p exerts metastatic properties and maintains epithelial cell adhesion molecule + cancer stem cells via HSPA8 in HCC (57). Moreover, a study investigating the role of PHLPP1 in HCC reported that miR-190 influences EMT by regulating the expression of PHLPP1, thus affecting the malignant biological behavior of HCC cells (58). Isobaric tags for relative and absolute quantification analysis of clinical samples of HCC indicated that ACTB serves an important role in the initiation stage of HCC (59). Long non-coding RNA ATRERNA1 promotes the metastasis and invasiveness of HCC cells by recruiting EHMT2 and/or ehmt2/snai1 complexes to inhibit CDH1 (60). Loss of NFKB1 promotes the occurrence of age-related chronic liver disease (CLD) which is characterized by steatosis, neutrophil proliferation, fibrosis, telomere damage of hepatocytes and HCC (61). The results of the present study demonstrated that STAT3 is one of the hub genes. Phosphorylated RPN2 activates the signal transducer and activator of STAT3 and is also responsible for the RPN2-stimulated elevated expression of MMP-9 and for invading HCC cells (62).

In the current study, biological function and signal pathway enrichment analysis revealed that the genes in module 1, 2 and 3 were primarily enriched in 'RNA splicing', 'G-protein coupled receptor signaling pathway' and 'protein ubiquitination'. Studies have demonstrated that these signaling pathways are required for cell survival and metabolism and serve an important role in tumor recurrence and metastasis (63-65). Therefore, it is hypothesized that these molecular pathways may provide novel insight and potential targets for the diagnosis and treatment of HCC.

In conclusion, 1,171 DEGs were identified (including 712 upregulated and 459 downregulated genes, 1,033 nodes, 7,589 edges and 10 hub genes) via gene profile dataset and integrated bioinformatics analysis in noncancerous surrounding hepatic tissues. The 10 hub genes were significantly enriched in several signaling pathways which serve an important role in tumor metastasis. According to the present research and analysis, CAD, GART, HSPA5, ACTB, CDH1 and HSPA8 may have potential as targets for the diagnosis and treatment of metastatic HCC. The present study may provide a scientific basis for the investigation of these genes in HCC in the future.

\section{Acknowledgements}

Not applicable.

\section{Funding}

The present study was supported by The Foundation of Scientific Research of Sichuan Medical Association (grant. no. S16007), The Sichuan Health Planning Commission
Key Project Foundation (grant. no. 17ZD008), The Sichuan Science and Technology Project (grant. no. 2018JY0276) and The Chengdu Science and Technology Bureau Technology Innovation Project (grant. no. 2018-YF05-01228-SN).

\section{Availability of data and materials}

The datasets generated and/or analyzed during the present study are available in the [NCBI] repository, [https://www. ncbi.nlm.nih.gov/geo]

\section{Authors' contributions}

YL and HW performed the experiments, analyzed the data and drafted the manuscript. YW, HW, MD and CL conceptualized the study design and critically revised the manuscript. YL, MD, CL and HW wrote the manuscript. All authors read and approved the final manuscript.

\section{Ethics approval and consent to participate}

The present study was approved by The Institutional Review Board of the Second Affiliated Hospital of Chongqing Medical University (Chongqing, China) and written informed consent was provided by all patients according to the Declaration of Helsinki.

\section{Patient consent for publication}

Not applicable.

\section{Competing interests}

The authors declare that they have no competing interests.

\section{References}

1. Siegel RL, Miller KD and Jemal A: Cancer statistics, 2016. CA Cancer J Clin 66: 7-30, 2016.

2. Chen WQ, Zheng RS, Baade PD, Zhang S, Zeng H, Bray F, Jemal A, Yu XQ and He J: Cancer statistics in China, 2015. CA Cancer J Clin 66: 115-132, 2016.

3. Greten TF, Wang XW and Korangy F: Current concepts of immune based treatments for patients with HCC: From basic science to novel treatment approaches. Gut 64: 842-848, 2015.

4. Pang RW, Joh JW, Johnson PJ, Monden M, Pawlik TM and Poon RT: Biology of hepatocellular carcinoma. Ann Surg Oncol 15: 962-971, 2008.

5. Ye QH, Qin LX, Forgues M, He P, Kim JW, Peng AC, Simon R, Li Y, Robles AI, Chen Y, et al: Predicting hepatitis B virus-positive metastatic hepatocellular carcinomas using gene expression profiling and supervised machine learning. Nat Med 9: 416-423, 2003.

6. Iizuka N, Oka M, Yamada-Okabe H, Nishida M, Maeda Y, Mori N, Takao T, Tamesa T, Tangoku A, Tabuchi H, et al: Oligonucleotide microarray for prediction of early intrahepatic recurrence of hepatocellular carcinoma after curative resection. Lancet 361: 923-929, 2003.

7. Budhu A, Forgues M, Ye QH, Jia HL, He P, Zanetti KA Kammula US, Chen Y, Qin LX, Tang ZY and Wang XW: Prediction of venous metastases, recurrence, and prognosis in hepatocellular carcinoma based on a unique immune response signature of the liver microenvironment. Cancer Cell 10: 99-111, 2006.

8. Tang Z, Li C, Kang B, Gao G, Li C and Zhang Z: GEPIA: A web server for cancer and normal gene expression profiling and interactive analyses. Nucleic Acids Res 45(W1): W98-W102, 2017. 
9. Szklarczyk D, Gable AL, Lyon D, Junge A, Wyder S, Huerta-Cepas J, Simonovic M, Doncheva NT, Morris JH, Bork P, et al: STRING v11: Protein-protein association networks with increased coverage, supporting functional discovery in genome-wide experimental datasets. Nucleic Acids Res 47: D607-D613, 2019.

10. Shannon P, Markiel A, Ozier O, Baliga NS, Wang JT, Ramage D, Amin N, Schwikowski B and Ideker T: Cytoscape: A software environment for integrated models of biomolecular interaction networks. Genome Res 13: 2498-2504, 2003.

11. Bader GD and Hogue CW: An automated method for finding molecular complexes in large protein interaction networks. BMC Bioinformatics 4: 2, 2003.

12. Livak KJ and Schmittgen TD: Analysis of relative gene expression data using real-time quantitative PCR and the 2(-Delta Delta C(T)) method. Methods 25: 402-408, 2001.

13. Thorgeirsson SS and Grisham JW: Molecular pathogenesis of human hepatocellular carcinoma. Nat Genet 31: 339-346, 2002.

14. Fan W and Ye G: Microarray analysis for the identification of specific proteins and functional modules involved in the process of hepatocellular carcinoma originating from cirrhotic liver. Mol Med Rep 17: 5619-5626, 2018.

15. Gulubova MV: Expression of cell adhesion molecules, their ligands and tumour necrosis factor alpha in the liver of patients with metastatic gastrointestinal carcinomas. Histochem J 34: 67-77, 2002.

16. Ploverini P: Cellular adhesion molecules; newly identified mediators of angiogenesis. Am J Pathol 148: 1023-1029, 1996.

17. McGrogan D and Bookstein R: Tumor suppressor genes in prostate cancer. Semin Cancer Biol 8: 11-19, 1997.

18. Folkman J: Tumor angiogenesis: Therapeutic implications. N Engl J Med 285: 1182-1186, 1971.

19. Folkman J: What is the evidence that tumors are angiogenesis dependent? J Natl Cancer Inst 82: 4-6, 1990.

20. Akiyama SK, Larjava $\mathrm{H}$ and Yamada KM: Differences in the biosynthesis and localization of the fibronectin receptor in normal and transformed cultured human cells. Cancer Res 50: 1601-1607, 1990

21. Koop S, Schmidt EE, MacDonald IC, Morris VL, Khokha R, Grattan M, Leone J, Chambers AF and Groom AC: Independence of metastatic ability and extravasation: Metastatic ras-transformed and control fibroblasts extravasate equally well. Proc Natl Acad Sci USA 93: 11080-11084, 1996.

22. Klein CA: Cancer. The metastasis cascade. Science 321: 1785-1787, 2008.

23. Chiang AC and Massagué J: Molecular basis of metastasis N Engl J Med 359: 2814-2823, 2008.

24. O'Donnell JP, Marsh HM, Sondermann H and Sevier CS: Disrupted hydrogen-bond network and impaired ATPase activity in an Hsc70 cysteine mutant. Biochemistry 57: 1073-1086, 2018

25. Mayer MP and Bukau B: Hsp70 chaperones: Cellular functions and molecular mechanism. Cell Mol Life Sci 62: 670-684, 2005

26. Xie W, Zhang L, Jiao H, Guan L, Zha J, Li X, Wu M, Wang Z, Han $\mathrm{J}$ and You H: Chaperone-mediated autophagy prevents apoptosis by degrading BBC3/PUMA. Autophagy 11: 1623-1635, 2015.

27. Majeski AE and Dice JF: Mechanisms of chaperone-mediated autophagy. Int J Biochem Cell Biol 36: 2435-2444, 2004.

28. Wang X, Wang Q, Lin H, Li S, Sun L and Yang Y: HSP72 and gp96 in gastroenterological cancers. Clin Chim Acta 417: 73-79, 2013.

29. Brognard $\mathbf{J}$ and Newton AC: PHLiPPing the switch on Akt and protein kinase C signaling. Trends Endocrinol Metab 19: 223-230, 2008

30. Qiao M, Iglehart JD and Pardee AB: Metastatic potential of $21 \mathrm{~T}$ human breast cancer cells depends on Akt/protein kinase B activation. Cancer Res 67: 5293-5299, 2007.

31. Hattori M, Fujiyama A, Taylor TD, Watanabe H, Yada T, Park HS Toyoda A, Ishii K, Totoki Y, Choi DK, et al: The DNA sequence of human chromosome 21. Nature 405: 311-319, 2000.

32. Banerjee D and Nandagopal K: Potential interaction between the GARS-AIRS-GART Gene and CP2/LBP-1c/LSF transcription factor in down syndrome-related Alzheimer disease. Cell Mol Neurobiol 27: 1117-1126, 2007.

33. Ng BG, Wolfe LA, Ichikawa M, Markello T, He M, Tifft CJ, Gahl WA and Freeze HH: Biallelic mutations in CAD, impai de novo pyrimidine biosynthesis and decrease glycosylation precursors. Hum Mol Genet 24: 3050-3057, 2015.

34. Gunning PW, Ghoshdastider U, Whitaker S, Popp D and Robinson RC: The evolution of compositionally and functionally distinct actin filaments. J Cell Sci 128: 2009-2019, 2015
35. Guo C, Liu S, Wang J, Sun MZ and Greenaway FT: ACTB in cancer. Clin Chim Acta 417: 39-44, 2013.

36. Cappell SD, Chung M, Jaimovich A, Spencer SL and Meyer T: Irreversible APC (Cdh1) inactivation underlies the point of no return for cell-cycle entry. Cell 166: 167-180, 2016

37. Beavon IR: The E-cadherin-catenin complex in tumour metastasis: Structure, function and regulation. Eur J Cancer 36: $1607-1620,2000$

38. Polyak K and Weinberg RA: Transitions between epithelial and mesenchymal states: Acquisition of malignant and stem cell traits. Nat Rev Cancer 9: 265-273, 2009.

39. Alloatti G, Montrucchio G, Lembo $G$ and Hirsch E: Phosphoinositide 3-kinase gamma: Kinase-dependent and -independent activities in cardiovascular function and disease. Biochem Soc Trans 32: 383-386, 2004

40. Rubio I, Wittig U, Meyer C, Heinze R, Kadereit D, Waldmann H, Downward $\mathbf{J}$ and Wetzker R: Farnesylation of Ras is important for the interaction with phosphoinositide 3-kinase gamma. Eur J Biochem 266: 70-82, 1999.

41. Uehara M, McGrath MM, Ohori S, Solhjou Z, Banouni N, Routray S, Evans C, DiNitto JP, Elkhal A, Turka LA, et al: Regulation of $\mathrm{T}$ cell alloimmunity by PI3K $\gamma$ and PI3Kס. Nat Commun 8: 951, 2017.

42. Concetti $\mathrm{J}$ and Wilson CL: NFKB1 and cancer: Friend or foe? Cells 7: E133, 2018.

43. Philip S, Bulbule A and Kundu GC: Matrix metalloproteinase-2: Mechanism and regulation of NF- $\kappa \mathrm{B}$-mediated activation and its role in cell motility and ECM-invasion. Glycoconj J 21: 429-441, 2004.

44. Bharti AC and Aggarwal BB: Nuclear factor-kappa B and cancer: Its role in prevention and therapy. Biochem Pharmacol 64: 883-888, 2002.

45. Wang Y, Shen Y, Wang S, Shen Q and Zhou X: The role of STAT3 in leading the crosstalk between human cancers and the immune system. Cancer Lett 415: 117-128, 2018.

46. Caetano MS, Hassane M, Van HT, Bugarin E, Cumpian AM, McDowell CL, Cavazos CG, Zhang H, Deng S, Diao L, et al: Sex specific function of epithelial STAT3 signaling in pathogenesis of K-ras mutant lung cancer. Nat Commun 9: 4589, 2018.

47. Wang J, Lee J, Liem D and Ping P: HSPA5 gene encoding Hsp70 chaperone $\mathrm{BiP}$ in the endoplasmic reticulum. Gene 618: 14-23, 2017.

48. Arap MA, Lahdenranta J, Mintz PJ, Hajitou A, Sarkis AS, Arap W and Pasqualini R: Cell surface expression of the stress response chaperone GRP78 enables tumor targeting by circulating ligands. Cancer Cell 6: 275-284, 2004.

49. Shuda M, Kondoh N, Imazeki N, Tanaka K, Okada T, Mori K, Hada A, Arai M, Wakatsuki T, Matsubara O, et al: Activation of the ATF6, XBP1 and grp78 genes in human hepatocellular carcinoma: A possible involvement of the ER stress pathway in hepatocarcinogenesis. J Hepatol 38: 605-614, 2003.

50. Um E, Oh JM, Granick S and Cho YK: Cell migration in microengineered tumor environments. Lab Chip 17: 4171-4185, 2017.

51. Condeelis $\mathbf{J}$ and Pollard JW: Macrophages: Obligate partners for tumor cell migration, invasion, and metastasis. Cell 124: 263-266, 2006

52. Yang Y, Zheng H, Zhan Y and Fan S: An emerging tumor invasion mechanism about the collective cell migration. Am J Transl Res 11: 5301-5312, 2019.

53. Denisenko TV, Gorbunova AS and Zhivotovsky B: Mitochondrial involvement in migration, invasion and metastasis. Front Cell Dev Biol 7: 355, 2019.

54. Li X, Miao Y, Pal DS and Devreotes PN: Excitable networks controlling cell migration during development and disease. Semin Cell Dev Biol: Dec 10, 2019 (Epub ahead of print) doi: 10.1016/j.semcdb.2019.11.001.

55. Mishra AK, Campanale JP, Mondo JA and Montell DJ: Cell interactions in collective cell migration. Development 146: dev172056, 2019.

56. Greenlee JD and King MR: Engineered fluidic systems to understand lymphatic cancer metastasis. Biomicrofluidics 14: 011502,2020

57. Misra UK, Payne S and Pizzo SV: The monomeric receptor binding domain of tetrameric; $\alpha 2$-macroglobulin binds to cell surface GRP78 triggering equivalent; activation of signaling cascades. Biochemistry 52: 4014-4025, 2013.

58. Khosla R, Hemati H, Rastogi A, Ramakrishna G, Sarin SK and Trehanpati N: MiR-26b-5p helps in EpCAM+cancer stem cells maintenance via HSC71/HSPA8 and augments malignant features in HCC. Liver Int 39: 1692-1703, 2019. 
59. Xiong Y, Wu S, Yu H, Wu J, Wang Y, Li H, Huang $\mathrm{H}$ and Zhang $\mathrm{H}$ : MiR-190 promotes HCC proliferation and metastasis by targeting PHLPP1. Exp Cell Res 371: 185-195, 2018.

60. Goh WW, Lee YH, Ramdzan ZM, Chung MC, Wong L and Sergot MJ: A network-based maximum link approach towards MS identifies potentially important roles for undetected ARRB $1 / 2$ and ACTB in liver cancer progression. Int J Bioinform Res Appl 8: 155-170, 2012.

61. Song W, Gu Y, Lu S, Wu H, Cheng Z, Hu J, Qian Y, Zheng Y and Fan H: LncRNA TRERNA1 facilitates hepatocellular carcinoma metastasis by dimethylating $\mathrm{H} 3 \mathrm{~K} 9$ in the $\mathrm{CDH} 1$ promoter region via the recruitment of the EHMT2/SNAI1 complex. Cell Prolif 52: e12621, 2019.

62. Wilson CL, Jurk D, Fullard N, Banks P, Page A, Luli S, Elsharkawy AM, Gieling RG, Chakraborty JB, Fox C, et al: $\mathrm{NF \kappa B1}$ is a suppressor of neutrophil-driven hepatocellular carcinoma. Nat Commun 6: 6818, 2015.
63. Black DL: Mechanisms of alternative pre-messenger RNA splicing. Annu Rev Biochem 72: 291-336, 2003.

64. King N, Hittinger CT and Carroll SB: Evolution of key cell signaling and adhesion protein families predates animal origins. Science 301: 361-363, 2003.

65. Mukhopadhyay D and Riezman H: Proteasome-independent functions of ubiquitin in endocytosis and signaling. Science 315 : 201-205, 2007.

This work is licensed under a Creative Commons Attribution-NonCommercial-NoDerivatives 4.0 International (CC BY-NC-ND 4.0) License. 